\title{
Características de carcaça em ovinos alimentados com rações contendo torta de mamona $^{1}$
}

\author{
Carcass characteristics of sheep fed rations containing castor cake
}

\author{
GOMES, Fernando Henrique Teixeira ${ }^{2 *}$; CÂNDIDO, Magno José Duarte ${ }^{2}$; \\ CARNEIRO, Maria Socorro de Souza ${ }^{2}$; FURTADO, Rafael Nogueira ${ }^{2}$; PEREIRA, \\ Elzânia Sales ; ; BOMFIM, Marco Aurélio Delmondes ${ }^{3}$; SOMBRA, Weberte Alan²; \\ BERNARDES, Diego Fernandes Vieira ${ }^{2}$
}

\footnotetext{
${ }^{1}$ Parte da dissertação de mestrado do primeiro autor.

${ }^{2}$ Universidade Federal do Ceará, Departamento de Zootecnia, Fortaleza, Ceará, Brasil.

${ }^{3}$ Embrapa Caprinos e Ovinos, Sobral, Ceará, Brasil.

*Endereço para correspondência: fernandohtg@gmail.com
}

\section{RESUMO}

Objetivou-se avaliar a influência de rações que continham torta de mamona em características de carcaça e componentes não carcaça de ovinos. Foram distribuídos 20 ovinos Morada Nova (peso inicial de $18,7 \pm 1,18 \mathrm{~kg}$ ) em blocos ao acaso, de acordo com o sexo (machos inteiros e fềmeas), com cinco tratamentos (torta de mamona não tratada, tratada com calcário calcítico, ureia, fosfato monobicálcico e autoclavada) e quatro repetições. Não houve diferença no consumo de matéria seca, ganho de peso total e peso ao abate entre tratamentos e, consequentemente, não ocorreu na maioria das variáveis analisadas entre tratamentos. No entanto, animais alimentados com torta autoclavada e torta tratada com fosfato monobicálcico foram superiores aos alimentados com torta de mamona não tratada. Quanto à perda ao jejum, houve diferença entre animais alimentados com torta autoclavada e com ureia, o que resultou em diferença no percentual de peso de corpo vazio. Animais alimentados com torta tratada com fosfato monobicálcico apresentaram maior peso de rúmen retículo em relação aos animais do tratamento ureia. A área de olho de lombo foi melhor nos animais alimentados com torta de mamona autoclavada seguido pelos animais que ingeriram torta tratada com fosfato monobicálcico. Em geral, a torta de mamona não tratada não prejudica as características de carcaça e seus não componentes.

Palavras-chave: confinamento, cortes de carcaça, destoxificação, rendimento de carcaça, Ricinus communis

\section{SUMMARY}

To evaluate the effects of rations containing castor cake on sheep carcass and non carcass components characteristics, this research was undertaken. Twenty Morada Nova sheep (initial weight of $18,7 \pm 1,18 \mathrm{~kg}$ ) were assigned to a complete randomized block design according to sex (whole males and females), with five treatments (castor cake untreated, castor cake treated with limestone, urea, phosphate monodicalcium and autoclaved) and four repetitions. There wasn't difference in dry matter intake, total weight gain and weight of slaughter between treatments and therefore didn't occur in most variables between treatments. However, animals fed with rations containing castor cake autoclaved and castor cake treated with phosphate monodicalcium were higher than those fed untreated castor cake. The loss in fast, there was difference between animals fed with rations containing castor cake autoclaved and animals fed with castor cake treated with urea, resulting also in difference in the percentage empty body weight. Animals fed with rations containing treated with phosphate monodicalcium had higher weight of rumen-reticulum in relation to the animals fed with ration containing castor cake treated with urea. The rib eye area was greater on animals fed castor cake autoclaved and treated with phosphate monodicalcium. In general, the castor cake untreated not affect carcass and non carcass components.

Keywords: confinement, commercial cuts, carcass yield, detoxification, Ricinus communis 


\section{INTRODUÇÃO}

A carne ovina é fonte de proteína de alto valor biológico e tem sido mais consumida nos últimos anos, o que tem elevado o grau de importância no mercado de carne. Entretanto, a cadeia agroindustrial nacional não tem eficiência na oferta do produto, pois geralmente os animais abatidos têm peso desuniforme e idade avançada, além de carne com baixa qualidade e de menor aceitação pelo consumidor (MACEDO et al., 2008). Uma opção para terminação de ovinos é em confinamento ou uso de pastagens de alta qualidade. Para ofertar ao consumidor animais jovens e melhor a qualidade da carcaça (REIS et al., 2001)

No confinamento a alimentação dos ovinos pode representar um gargalo, ao se ter em vista que economicamente representa grande parcela dos custos variáveis. Assim, tem-se buscado alternativas que aumentem o retorno econômico sem prejudicar as características de carcaça. Nesse contexto, um subproduto com potencial de utilização na alimentação de ovinos é a torta de mamona, uma vez que esta possui considerável teor de proteína, é produzida no Nordeste brasileiro e apresenta baixos custos de aquisição.

A torta de mamona contém uma proteína tóxica, a ricina (AUDI et al., 2005), que ainda é limitante para sua utilização na alimentação animal. Anandan et al. (2005) obtiveram 100\% de eliminação da ricina quando trataram a torta de mamona em autoclavagem (15psi/60min) e solução de hidróxido de cálcio, com $40 \mathrm{~g} \quad \mathrm{Ca}(\mathrm{OH})_{2} / \mathrm{kg}$ torta mamona. Já foi observado que a ingestão da semente de mamona por ruminantes pode causar intoxicação e até morte desses animais (ASLANI et al., 2007) embora alguns trabalhos demonstrem que o farelo e torta de mamona não tratadas não causam intoxicação nestes (DINIZ et al., 2010; OLIVEIRA et al., 2010). Dessa forma, necessita-se avaliar a utilização da torta de mamona na alimentação de ovinos terminados em confinamento, no Nordeste brasileiro, por meio de estudos das características de carcaça, e assim poder verificar possíveis alterações no produto final.

Objetivou-se avaliar a influência de rações que continham torta de mamona em características de carcaça e de componentes não carcaça de ovinos confinados.

\section{MATERIAL E MÉTODOS}

O experimento foi conduzido em Fortaleza, CE, no Núcleo de Ensino e Estudos em Forragicultura-NEEF/DZ/UFC (3'43'02'S e $\left.38^{\circ} 32^{\prime} 35^{\prime \prime} \mathrm{W}\right)$. A torta de mamona (TM) foi obtida a partir da extração mecânica do óleo da semente (90 a $110^{\circ} \mathrm{C}$ ), em Quixeramobim, CE. Foram utilizados vinte ovinos mestiços de Morada Nova, sendo 10 machos inteiros e 10 fêmeas, com peso médio inicial de $18,7 \pm 1,18 \mathrm{~kg}$ e cerca de 240 dias de idade. Os animais foram desverminados, suplementados com vitaminas A, D e E, e confinados em baias individuais de $1 \mathrm{~m}^{2}$, providas de comedouros e bebedouros.

A escolha dos métodos de destoxificação da torta de mamona que constituíram os tratamentos foi realizada com base em eletroforese em gel de poliacrilamida (FURTADO, 2010), considerados mais eficientes os agentes que promoveram maior desaparecimento das subunidades da ricina. Alguns desses (autoclave, ureia e calcário calcítico) foram baseados em métodos avaliados por Anandan et al. (2005) (autoclave, amônia e hidróxido de cálcio). Então, os cinco tratamentos foram: torta de mamona não tratada 
(controle), ou tratada com calcário calcítico, ou tratada com ureia, ou tratada com fosfato monobicálcico ou autoclavada, em delineamento de blocos ao acaso com quatro repetições (ovinos). Foram formados dois blocos, a partir do sexo, e cada animal representou uma unidade experimental. A utilização da TM não tratada foi baseada em ensaios preliminares de Furtado (2010).

O tratamento da torta de mamona foi realizado pela diluição do agente químico em água nas seguintes proporções: $60 \mathrm{~g}$ de calcário calcítico $/ 500 \mathrm{~mL}$ água $/ \mathrm{kg} \mathrm{TM}$; $60 \mathrm{~g}$ de fosfato monobicálcico $/ 500 \mathrm{~mL}$ água/kg TM; e $10 \mathrm{~g}$ de ureia/500mL água $/ \mathrm{kg}$ TM. A torta foi tratada homogeneamente, mediante aplicação com auxílio de baldes e utilização de pás para revolver a massa. Posteriormente, foram mantidas em tambores por oito horas (à noite), as tortas tratadas com calcário calcítico ou com fosfato monobicálcico, e por sete dias, a tratada com ureia. Finalmente, a tortas tratadas, dos três tratamentos descritos anteriormente, foram expostas ao sol, sobre lonas, até a secagem ( $90 \% \mathrm{MS})$. Esses procedimentos e a autoclavagem (15 psi a $123^{\circ} \mathrm{C}$, por $60 \mathrm{~min}$ ) foi baseado em Anandan et al. (2005). Durante a diluição do agente químico, mediu-se o pH, com auxílio de peagâmetro digital e obtiveram-se os valores: calcário calcítico, 7; ureia, 7; e fosfato monobicálcico, 4. As rações experimentais (Tabela 1) foram formuladas conforme NRC (2007), mediante utilização da relação volumoso:concentrado de 50:50. O período experimental foi de 70 dias, dos quais 14 dias iniciais para adaptação dos animais. As rações foram fornecidas duas vezes ao dia, $50 \%$ às $8 \mathrm{~h}$ e $50 \%$ às $16 \mathrm{~h}$, e coletadas sobras no dia seguinte para determinação do consumo diário e controle do nível de sobras, mantido em 15 a $20 \%$.
Após 70 dias de confinamento os animais foram pesados antes do jejum para obter o peso vivo (PV), determinando-se ganho de peso total, e só depois submetidos ao jejum de alimentos sólidos e líquidos por $16 \mathrm{~h}$, para caracterizar o peso vivo ao abate (PVAJ), determinar, assim, a perda devida ao jejum (PJ).

Antes do abate foram avaliadas, as medidas biométricas com os animais em pé sobre superfície plana e mediante a utilização de fita métrica e bastão zoométrico, tais como: comprimento corporal (CC), altura anterior (AA), altura posterior (AP), largura do peito (LP), largura da garupa (LG) e perímetro toráxico (PT). Também foi determinada a compacidade corporal (COMPAC):

$\mathrm{COMPAC}=\mathrm{PVAJ} / \mathrm{CC}$.

No abate, os animais foram insensibilizados, por atordoamento na região atla-occipital, seguida de sangria por cerca de quatro minutos mediante secção das carótidas e jugular, e foi recolhido $o$ sangue em balde. Posteriormente, foram realizadas esfola e evisceração, e retirados os constituintes não carcaça para serem pesados, os quais foram compostos por: traquéia + esôfago + pulmões + língua; fígado, coração, rins, baço, diafragma, sistema reprodutivo, bexiga, vesícula biliar; rúmen, retículo, omaso, abomaso e intestinos delgado e grosso; sangue, pele, cabeça, patas, gorduras omental, mesentérica, perirenal e do coração. Os componentes do trato gastrointestinal foram pesados "cheios" após jejum de 16 horas, sendo esvaziados, lavados e novamente pesados, para determinação do conteúdo do trato gastrointestinal (CTGI). O peso do corpo vazio foi obtido pela equação:

PCVZ $=$ PVAJ - CTGI. 
Tabela 1. Composição percentual e químico-bromatológica das rações experimentais

\begin{tabular}{|c|c|c|c|c|c|}
\hline \multirow{2}{*}{ Componentes } & \multicolumn{5}{|c|}{ Método de destoxificação ${ }^{5}$} \\
\hline & NT & $\mathrm{CC}$ & UR & FOS & ACL \\
\hline & \multicolumn{5}{|c|}{ Ingredientes da ração (\% na MS) } \\
\hline Feno de capim-tifton 85 & 49,31 & 49,54 & 49,54 & 49,42 & 48,68 \\
\hline Fubá de milho & 34,47 & 34,51 & 34,31 & 34,36 & 34,90 \\
\hline Torta de mamona & 8,11 & 8,11 & 8,07 & 8,08 & 8,21 \\
\hline Farelo de soja & 4,05 & 4,07 & 4,04 & 4,04 & 4,10 \\
\hline Farelo de trigo & 2,79 & 2,78 & 2,78 & 2,78 & 2,82 \\
\hline Sal mineral ${ }^{1}$ & 0,507 & 0,508 & 0,505 & 0,505 & 0,513 \\
\hline Calcário calcítico & 0,283 & 0 & 0,282 & 0,334 & 0,286 \\
\hline Uréia & 0,253 & 0,253 & 0,252 & 0,253 & 0,257 \\
\hline Sal comum $(\mathrm{NaCl})$ & 0,203 & 0,203 & 0,202 & 0,202 & 0,205 \\
\hline \multirow[t]{2}{*}{ Sulfato de amônio } & 0,025 & 0,025 & 0,025 & 0,025 & 0,025 \\
\hline & \multicolumn{5}{|c|}{ Composição químico-bromatológica } \\
\hline Matéria seca - MS (g/kg MN) & 860 & 856 & 856 & 858 & 871 \\
\hline Matéria orgânica (g/kg MN) & 945 & 945 & 946 & 943 & 944 \\
\hline Matéria mineral (g/kg MS) & 55,4 & 55,0 & 53,7 & 56,8 & 56,4 \\
\hline Extrato etéreo (g/kg MS) & 24,5 & 22,2 & 22,6 & 25,7 & 25,3 \\
\hline Proteína bruta (g/kg MS) & 119 & 120 & 116 & 116 & 120 \\
\hline $\mathrm{NIDN}^{2}$ (\% Nitrogênio total) & 29,6 & 29,0 & 29,9 & 30,9 & 30,8 \\
\hline NIDA $^{2}$ (\% Nitrogênio total) & 4,18 & 4,22 & 4,18 & 4,01 & 3,85 \\
\hline Fibra em detergente neutro (g/kg MS) & 534 & 526 & 557 & 552 & 546 \\
\hline $\mathrm{FDN}_{\mathrm{cp}}{ }^{4}(\mathrm{~g} / \mathrm{kg} \mathrm{MS})$ & 521 & 515 & 543 & 539 & 532 \\
\hline Fibra em detergente ácido (g/kg MS) & 244 & 245 & 239 & 241 & 239 \\
\hline Carboidratos não fibrosos (g/kg MS) & 280 & 288 & 265 & 262 & 266 \\
\hline
\end{tabular}

${ }^{\mathrm{T}}$ Composição (nutrientes/kg): fosfato, 65,0g; cálcio, 160,0g; enxofre, 15,0g; magnésio, 6,5g; sódio, 150,0g; cobalto, 0,125g; zinco, 4,5g; ferro, 1,7g; manganês, 4,5g; iodo, $0,06 \mathrm{~g}$; selênio, $0,03 \mathrm{~g}$; flúor, $0,95 \mathrm{~g} .{ }^{2} \%$ nitrogênio total. ${ }^{2} \mathrm{NIDN}$ : nitrogênio insolúvel em detergente neutro; ${ }^{3} \mathrm{NIDA}$ : nitrogênio insolúvel em detergente ácido; ${ }^{4} \mathrm{FDN}_{\mathrm{cp}}$ : fibra em detergente neutro corrigido para cinza e proteína; ${ }^{5} \mathrm{NT}$ : ração contendo torta de mamona não tratada.

$\mathrm{CC}=$ ração contendo torta de mamona tratada com calcário calcítico; UR = ração contendo torta de mamona tratada com uréia; FOS = ração contendo torta de mamona tratada com fosfato monobicálcico; $\mathrm{ACL}=$ ração contendo torta de mamona autoclavada. 
Após a separação dos componentes não carcaça foi obtido $\mathrm{o}$ peso de carcaça quente (PCQ), em seguida acondicionadas em sacos plásticos, resfriadas a $5^{\circ} \mathrm{C}$ por 24 horas em câmara frigorífica, e decorrido esse tempo foram pesadas para a obtenção do peso de carcaça fria (PCF). Para a determinação da perda de peso por resfriamento (PR), rendimentos verdadeiro (RV), comercial (RC) e biológico (RB), foram utilizadas as equações:

$\mathrm{PR}=100[(\mathrm{PCQ}-\mathrm{PCF}) / \mathrm{PCQ}] ; \mathrm{RV}=100(\mathrm{PCQ} / \mathrm{PVAJ}) ; \mathrm{RC}=100(\mathrm{PCF} / \mathrm{PVAJ}) ; \mathrm{RB}=$ 100(PCQ/PCVZ).

Após a pesagem foram efetuadas medidas das carcaças, com as articulações tarso metatarsianas mantidas a $14 \mathrm{~cm}$ entre si, penduradas com ganchos. Foram realizadas as seguintes mensurações: comprimento externo da carcaça (CEC), comprimento interno da carcaça (CIC), comprimento da perna (CP), largura da garupa (LG), largura do tórax (LT), largura anterior (LA), perímetro da garupa (PG), perímetro do tórax (PT) e perímetro da perna (PP). As compacidades de carcaça (ICC) e perna (ICP) foram determinadas pelas equações:

$\mathrm{ICC}=\mathrm{PCF} / \mathrm{CIC}$; ICP $=\mathrm{LG} / \mathrm{CP}$.

Dividiu-se longitudinalmente a carcaça em esquerda e direita, seccionou-se a meia carcaça esquerda em oito cortes comerciais (GETTY, 1986): perna, lombo (anterior e posterior), paleta, costela, peito, fraldinha e pescoço. Os pesos individuais dos cortes foram divididos pelo peso da meia carcaça esquerda fria, o que permitiu o cálculo das proporções dos cortes. $\mathrm{Na}$ meia-carcaça direita realizou-se corte transversal entre $12^{\mathrm{a}}$ e $13^{\mathrm{a}}$ costelas, expondo a secção transversal do músculo Longissimus lumborun, cuja área foi tracejada sobre película plástica transparente para determinação da área de olho de lombo, por meio de planímetro.

Os dados foram submetidos à análise de variância e teste de comparação de médias pelo teste de Tukey $(\mathrm{P}<0,05)$, com auxílio do procedimento GLM do SAS INSTITUTE (2003).

\section{RESULTADOS E DISCUSSÃO}

O consumo de matéria seca (MS) não foi influenciado $(\mathrm{P}>0,05)$ pelos tratamentos de destoxificação, bem como o ganho de peso total (Tabela 2), ao se ter em vista que as rações foram isonutricionais e que não ocorreram sintomas de intoxicação aguda nos animais, haja vista a capacidade da microbiota ruminal em degradar a ricina (OLIVEIRA et al., 2010), resultando assim, em peso vivo (PV) semelhante entre tratamentos. Essa semelhança no crescimento proporcionou, em geral, que as medidas corporais não fossem influenciadas $(\mathrm{P}>0,05)$ pelos tratamentos de destoxificação da torta de mamona (Tabela 2). No entanto, os animais alimentados com torta tratada com fosfato monobicálcico (TMFOS) e autoclavada (TMACL) foram superiores aos alimentados com torta não tratada (NT) para o perímetro toráxico, o que pode ter relação com os maiores valores absolutos de ganho de peso total desses tratamentos.

Não houve diferenças $(\mathrm{P}>0,05)$ entre tratamentos de destoxificação para peso vivo de abate (PVAJ), peso de corpo vazio (PCVZ) em $\mathrm{kg}$, peso da carcaça quente (PCQ), peso da carcaça fria (PCF), perda por resfriamento (PR), rendimento verdadeiro $(\mathrm{RV})$, rendimento biológico (RB) e rendimento comercial (RC). 
Tabela 2. Medidas biométricas e características de carcaça de ovinos alimentados com rações contendo torta de mamona submetida a diferentes métodos de destoxificação

\begin{tabular}{|c|c|c|c|c|c|c|}
\hline \multirow{2}{*}{ Item } & \multicolumn{5}{|c|}{ Método de destoxificação ${ }^{1}$} & \multirow{2}{*}{ CV (\%) } \\
\hline & NT & $\mathrm{CC}$ & UR & FOS & $\mathrm{ACL}$ & \\
\hline Consumo de MS (g/animal•dia) & 860,2 & 889,2 & 830,5 & 967,5 & 974,2 & 15,17 \\
\hline Ganho de peso total $(\mathrm{kg})$ & 9,55 & 11,0 & 9,05 & 11,7 & 11,9 & 23,09 \\
\hline Comprimento corporal $(\mathrm{cm})$ & 60,1 & 60,7 & 59,6 & 62,0 & 62,3 & 3,97 \\
\hline Altura anterior $(\mathrm{cm})$ & 60,2 & 60,4 & 59,1 & 60,0 & 60,3 & 3,28 \\
\hline Altura posterior $(\mathrm{cm})$ & 61,6 & 61,9 & 60,2 & 60,6 & 60,6 & 3,83 \\
\hline Largura do peito $(\mathrm{cm})$ & 16,3 & 17,2 & 16,6 & 17,7 & 17,5 & 6,41 \\
\hline Largura da garupa $(\mathrm{cm})$ & 15,8 & 15,9 & 15,7 & 16,7 & 16,4 & 8,98 \\
\hline Perímetro toráxico $(\mathrm{cm})$ & $68,0^{\mathrm{b}}$ & $69,6^{\mathrm{ab}}$ & $69,0^{\mathrm{ab}}$ & $72,3^{\mathrm{a}}$ & $71,5^{\mathrm{a}}$ & 3,21 \\
\hline Compacidade corporal $(\mathrm{kg} / \mathrm{cm})$ & 0,452 & 0,470 & 0,435 & 0,477 & 0,470 & 7,50 \\
\hline Peso vivo $(\mathrm{kg})$ & 29,0 & 30,3 & 27,6 & 31,6 & 31,5 & 9,76 \\
\hline Peso vivo ao abate $(\mathrm{kg})$ & 27,2 & 28,5 & 26,0 & 29,7 & 29,2 & 10,0 \\
\hline Peso de corpo vazio $(\mathrm{kg})$ & 22,8 & 24,0 & 22,1 & 25,0 & 24,2 & 10,0 \\
\hline Peso de corpo vazio $(\%)$ & $78,7^{\mathrm{ab}}$ & $79,1^{\mathrm{ab}}$ & $80,1^{\mathrm{a}}$ & $79,4^{\mathrm{ab}}$ & $77,0^{\mathrm{b}}$ & 2,10 \\
\hline Perda ao jejum $(\mathrm{kg})$ & $1,77^{\mathrm{ab}}$ & $1,82^{\mathrm{ab}}$ & $1,60^{\mathrm{b}}$ & $1,85^{\mathrm{ab}}$ & $2,25^{\mathrm{a}}$ & 21,8 \\
\hline Peso de carcaça quente $(\mathrm{kg})$ & 13,1 & 13,6 & 12,4 & 14,3 & 14,0 & 10,1 \\
\hline Peso de carcaça fria $(\mathrm{kg})$ & 12,8 & 13,2 & 12,1 & 14,0 & 13,7 & 9,93 \\
\hline Perda por resfriamento $(\%)$ & 2,74 & 2,73 & 2,23 & 2,39 & 2,26 & 22,9 \\
\hline Rendimento verdadeiro (\%) & 48,3 & 47,7 & 47,8 & 48,4 & 48,0 & 2,48 \\
\hline Rendimento biológico (\%) & 57,5 & 56,7 & 56,3 & 57,5 & 57,9 & 1,95 \\
\hline Rendimento comercial (\%) & 46,9 & 46,4 & 46,7 & 47,2 & 46,9 & 2,63 \\
\hline
\end{tabular}

MS = matéria seca; Médias dos métodos de destoxificação na mesma linha, seguidas de letras minúsculas diferentes, diferem entre si (P<0,05) pelo teste de Tukey.

${ }^{1} \mathrm{NT}$ : ração contendo torta de mamona não tratada; CC: ração contendo torta de mamona tratada com calcário calcítico; UR: ração contendo torta de mamona tratada com uréia; FOS: ração contendo torta de mamona tratada com fosfato monobicálcico; ACL: ração contendo torta de mamona autoclavada. 
Entretanto, é válido ressaltar que, considerados os valores absolutos, notaram-se aumentos de 8,96; 9,19; 9,65; 9,16; 9,37\% de PV, PVAJ, PCVZ (kg), PCQ, PCF dos animais que ingeriam TMFOS em relação aos alimentados com NT, e 8,$62 ; 7,35 ; 6,14 ; 6,87 ; 7,03 \%$ de PC, PVAJ, PCVZ, PCQ, PCF dos animais que ingeriam TMACL em relação aos animais do tratamento NT. Isso pode ter relação com o consumo de MS, que apesar da ausência de diferença entre tratamentos e considerados seus valores absolutos foi maior $114,0 \mathrm{~g} /$ animal $\bullet$ dia, para animais que ingeriam ração com torta de mamona autoclavada, e 107,3g/animal•dia, para animais que consumiam ração que continha torta de mamona tratada com fosfato monobicálcico, em relação aos animais alimentados com ração que continha torta de mamona não tratada, o que proporcionou valor absoluto de ganho de peso total maior de $2,35 \mathrm{e}$ $2,15 \mathrm{~kg}$, dos animais alimentados com TMACL e TMFOS em relação aos que ingeriram NT, respectivamente. Embora a microbiota ruminal fosse capaz de degradar a ricina, o que reduz a ação tóxica no animal hospedeiro, a toxina ainda pode ter alguma inibição sobre o crescimento microbiano (OLIVEIRA et al., 2010), e pode causar efeitos subclínicos em ovinos. Com isso, os tratamentos de destoxificação podem ter apresentado efeito, quando se utiliza tratamento ácido, como solução de fosfato monobicálcico ( $\mathrm{pH} 4,0)$, os valores de $\mathrm{pH}$ ficam inferiores ao ponto isoelétrico $(\mathrm{pI})$ da ricina de 5,2 a 5,5 (KABAT et al., 1947), o que torna a carga líquida da proteína positiva e, esse excesso de cargas do mesmo sinal, pode causar repulsão eletrostática e resultar em rompimentos das ligações fracas, pontes de hidrogênio $(\mathrm{H})$, que mantém a estrutura terciária da proteína (LEHNINGER et al., 1995). Quanto à autoclavagem foi verificado por Anandan et al. (2005) que este método causa completa destruição da ricina. Quanto à perda ao jejum (PJ), houve diferença $(\mathrm{P}<0,05)$ entre animais dos tratamentos autoclave e ureia, em virtude dos ovinos de maior peso e desenvolvimento geralmente apresentarem maior desenvolvimento e conteúdo do aparelho digestivo (BURRIN et al., 1990), o que resultou em diferença $(\mathrm{P}<0,05)$ na $\%$ PCVZ entre animais desses tratamentos. Não houve influência $(\mathrm{P}>0,05)$ dos tratamentos em PR, RV, RB e RC, cuja média foi de 2,47; 48,05; 57,15 e 46,85\%, respectivamente. Não houve diferenças entre tratamentos para $\mathrm{RV}, \mathrm{RB}$ e $\mathrm{RC}$, devido à semelhança entre estes no PCQ, PCF, PVAJ e PCVZ (kg). Vieira et al. (2010) observaram RV, RB e RC inferiores, de 43,4; 55,59 e 42,84\%, em ovinos Morada Nova alimentados com 52 a $72 \%$ de concentrado, obtendo PVAJ superior $(29,08 \mathrm{~kg})$, mas menores PCQ $(12,61 \mathrm{~kg})$ e PCF $(12,45 \mathrm{~kg})$, o que reduziu o rendimento de carcaça.

Peso e rendimento dos cortes não foram influenciados $(\mathrm{P}>0,05)$ pelos tratamentos (Tabela 3), devido à semelhança entre estes no PCF, resultante do ganho de peso total semelhante nestes. A média dos rendimentos dos cortes foi: perna $(31,15 \%)$, lombo anterior $(14,45 \%)$, lombo posterior $(5,66 \%)$, paleta $(17,3 \%)$, costela $(6,21 \%)$, peito $(5,76 \%)$, fraldinha $(9,14 \%)$ e pescoço $(10,24 \%)$. O percentual médio dos cortes foi: de primeira, 51,3\%; de segunda, $17,3 \%$; e de terceira, $31,4 \%$, o que mostra que os cortes de maior valor comercial, como perna, paleta (FRESCURA et al., 2005) e lombo (PINHEIRO et al., 2007), representam significativa parcela da carcaça. A semelhança na composição regional da carcaça também foi observada por Osório et al. (2002) que ao estudarem produção de carne em animais cruzas de Border Leicester com ovelhas Ideal e 
Rev. Bras. Saúde Prod. Anim., Salvador, v.13, n.1, p.283-295 jan/mar, 2012 http://www.rbspa.ufba.br ISSN 15199940

ovelhas Corriedale verificaram que a maioria dos cortes da carcaça apresentaram semelhança no peso e no rendimento, para esses genótipos. Em geral, não houve diferença $(\mathrm{P}>0,05)$ no rendimento dos cortes, o que mostra crescimento proporcional dos cortes em relação ao aumento de PV, e corrobora com Siqueira et al. (2001).

Tabela 3. Peso e rendimento dos cortes comerciais de ovinos alimentados com rações contendo torta de mamona submetida a diferentes métodos de destoxificação

\begin{tabular}{llccccc}
\hline \multirow{2}{*}{ Item } & \multicolumn{5}{c}{ Método de destoxificação } & \multirow{2}{*}{ CV (\%) } \\
\cline { 2 - 6 } & $\mathrm{NT}$ & $\mathrm{CC}$ & $\mathrm{UR}$ & $\mathrm{FOS}$ & $\mathrm{ACL}$ & \\
\hline Perna & 1,96 & 2,03 & 1,86 & 2,11 & 2,07 & 8,77 \\
Lombo anterior & 0,927 & 0,927 & 0,850 & 0,992 & 0,982 & 10,99 \\
Lombo posterior & 0,352 & 0,362 & 0,350 & 0,375 & 0,385 & 14,45 \\
Paleta & 1,13 & 1,12 & 1,04 & 1,17 & 1,14 & 10,09 \\
Costela & 0,350 & 0,407 & 0,410 & 0,405 & 0,430 & 23,02 \\
Peito & 0,345 & 0,357 & 0,345 & 0,412 & 0,405 & 15,35 \\
Fraldinha & 0,577 & 0,585 & 0,535 & 0,647 & 0,615 & 13,44 \\
Pescoço & 0,630 & 0,665 & 0,630 & 0,730 & 0,697 & 18,26 \\
Perna & 31,4 & 31,6 & 30,9 & 31,0 & 30,8 & 4,16 \\
Lombo anterior & 14,6 & 14,4 & 14,1 & 14,5 & 14,6 & 7,64 \\
Lombo posterior & 5,62 & 5,59 & 5,86 & 5,55 & 5,73 & 13,21 \\
Paleta & 18,0 & 17,4 & 17,3 & 17,0 & 17,0 & 4,27 \\
Costela & 5,61 & 6,26 & 6,81 & 5,97 & 6,43 & 17,37 \\
Peito & 5,54 & 5,52 & 5,72 & 6,03 & 5,97 & 13,31 \\
Fraldinha & 9,16 & 9,01 & 8,91 & 9,44 & 9,18 & 11,12 \\
Pescoço & 10,0 & 10,1 & 10,3 & 10,5 & 10,3 & 10,40 \\
\hline
\end{tabular}

Médias dos métodos de destoxificação na mesma linha, seguidas de letras minúsculas diferentes, diferem entre si $(\mathrm{P}<0,05)$ pelo teste de Tukey.

${ }^{1} \mathrm{NT}=$ ração contendo torta de mamona não tratada; $\mathrm{CC}=$ ração contendo torta de mamona tratada com calcário calcítico; UR = ração contendo torta de mamona tratada com uréia; FOS = ração contendo torta de mamona tratada com fosfato monobicálcico; ACL = ração contendo torta de mamona autoclavada.

Medeiros et al. (2009) relataram pesos de: perna, 2,05kg; lombo, 0,639kg; paleta, $1,18 \mathrm{~kg}$; e pescoço, $0,681 \mathrm{~kg}$, em ovinos Morada Nova alimentados com rações que continham $50 \%$ de concentrado. Já Gonzaga Neto et al. (2006) observaram pesos desses cortes de $1,75 \mathrm{~kg}, 0,67 \mathrm{~kg}, 1,06 \mathrm{~kg}$ e $0,51 \mathrm{~kg}$, respectivamente, em animais desta raça alimentados com rações que continham $60 \%$ de concentrado. Esses pesos de cortes estão próximos aos observados no presente trabalho, sendo maior a diferença no lombo, visto que a região delimitada para este corte foi diferente.

Não houve diferença $(\mathrm{P}>0,05)$ da maioria das medidas da carcaça entre tratamentos (Tabela 4), e isto reflete também o crescimento semelhante dos animais, dado a ausência de diferença no ganho de peso total, o que produziu carcaças com medidas de tamanho semelhantes entre tratamentos. Entretanto, a diferença existente em termos absolutos, no ganho de peso total, pode ter interferido na área de olho de lombo (AOL), que apresentou- 
se superior $(\mathrm{P}<0,05)$ nas carcaças dos animais dos tratamentos autoclave $\mathrm{e}$ fosfato monobicálcico, sendo relacionado ao maior crescimento muscular, notado pelo peso de abate e de carcaça numericamente maior. Zundt et al. (2003), ao estudarem carcaças de ovinos machos e fêmeas terminados em confinamento com rações que continham diferentes níveis proteicos verificaram que o peso vivo apresentou efeito linear sobre área de olho de lombo. A média da
AOL foi de $9,13 \mathrm{~cm}^{2}$, tendo os animais alimentados com torta de mamona autoclavada AOL semelhante à relatada $\left(11,24 \mathrm{~cm}^{2}\right)$ por Medeiros et al. (2009), para ovinos alimentados com níveis de concentrado. Entretanto, Gonzaga Neto et al. (2006), ao trabalharem com ovinos alimentados com relação volumoso:concentrado 50:50, obtiveram $\mathrm{AOL}\left(6,83 \mathrm{~cm}^{2}\right)$ inferior à do presente trabalho, tendo em vista o menor peso ao abate daqueles $(22,97 \mathrm{~kg})$.

Tabela 4. Medidas da carcaça de ovinos alimentados com rações contendo torta de mamona submetida a diferentes métodos de destoxificação

\begin{tabular}{lcccccc}
\hline \multirow{2}{*}{ Item } & \multicolumn{4}{c}{ Método de destoxificação } & CV \\
\cline { 2 - 6 } & NT & CC & UR & FOS & ACL & $(\%)$ \\
\hline Comprimento externo $(\mathrm{cm})$ & 56,4 & 55,7 & 55,6 & 55,2 & 55,6 & 3,59 \\
Comprimento interno $(\mathrm{cm})$ & 66,5 & 65,5 & 64,0 & 65,1 & 64,9 & 3,36 \\
Comprimento da perna $(\mathrm{cm})$ & 38,7 & 38,1 & 37,7 & 36,9 & 37,5 & 3,82 \\
Largura da garupa $(\mathrm{cm})$ & 19,4 & 18,7 & 18,6 & 18,2 & 18,9 & 3,30 \\
Largura do tórax $(\mathrm{cm})$ & 17,2 & 17,2 & 17,0 & 17,5 & 18,0 & 5,15 \\
Largura anterior $(\mathrm{cm})$ & 15,0 & 14,5 & 14,2 & 14,9 & 14,9 & 7,32 \\
Perímetro da garupa $(\mathrm{cm})$ & 55,7 & 58,4 & 56,4 & 59,7 & 59,2 & 4,25 \\
Perímetro do tórax $(\mathrm{cm})$ & 65,7 & 67,4 & 64,9 & 66,8 & 67,9 & 2,78 \\
Perímetro da perna $(\mathrm{cm})$ & 39,5 & 41,8 & 39,6 & 41,7 & 42,7 & 6,07 \\
Área de olho de lombo $\left(\mathrm{cm}{ }^{2}\right)$ & $8,30^{\text {bc }}$ & $8,75^{\text {bc }}$ & $8,05^{\mathrm{c}}$ & $9,80^{\text {ab }}$ & $10,8^{\mathrm{a}}$ & 44,8 \\
Compacidade da carcaça $(\mathrm{kg} / \mathrm{cm})$ & 0,192 & 0,201 & 0,190 & 0,214 & 0,212 & 8,27 \\
Compacidade da perna $(\mathrm{cm} / \mathrm{cm})$ & 0,500 & 0,491 & 0,493 & 0,493 & 0,505 & 4,10 \\
\hline
\end{tabular}

Médias dos métodos de destoxificação na mesma linha, seguidas de letras minúsculas diferentes, diferem entre si $(\mathrm{P}<0,05)$ pelo teste de Tukey.

${ }^{1} \mathrm{NT}=$ ração contendo torta de mamona não tratada; $\mathrm{CC}=$ ração contendo torta de mamona tratada com calcário calcítico; UR = ração contendo torta de mamona tratada com uréia; FOS = ração contendo torta de mamona tratada com fosfato monobicálcico; $\mathrm{ACL}$ = ração contendo torta de mamona autoclavada.

Não houve efeito $(\mathrm{P}>0,05)$ dos tratamentos para a maioria dos componentes corporais (Tabela 5). Os órgãos viscerais participam ativamente no metabolismo de nutrientes (FERREL \& JENKINS, 1985), mas, como não houve grandes diferenças nos níveis nutricionais das rações, bem como no consumo de matéria seca, não ocorreram diferenças desses órgãos entre tratamentos. $O$ coração tem importância vital, o qual cresce em fase mais precoce da vida do animal, não sendo influenciado pelo nível de energia consumido (BERG \& BUTTERFIELD, 1976). Alves et al. (2003) corroboram o presente trabalho, visto que não observaram diferença no peso do coração e aparelho respiratório ao trabalharem com níveis de energia para ovinos Santa Inês. Entretanto, quando se relacionou o peso total dos órgãos 
Rev. Bras. Saúde Prod. Anim., Salvador, v.13, n.1, p.283-295 jan/mar, 2012 http://www.rbspa.ufba.br ISSN 15199940

com PVAJ e PCVZ, observou-se diferença $(\mathrm{P}<0,05)$ dos animais do tratamento que envolvia torta de mamona tratada com ureia em relação aos demais, pois, em termos absolutos, as médias de PVAJ e PCVZ dos animais alimentados com torta tratada com ureia foram menores.

Tabela 5. Peso dos componentes do peso vivo de ovinos alimentados com rações contendo torta de mamona submetida a diferentes métodos de destoxificação

\begin{tabular}{|c|c|c|c|c|c|c|}
\hline \multirow{2}{*}{ Item $^{1}$} & \multicolumn{5}{|c|}{ Método de destoxificação ${ }^{2}$} & \multirow{2}{*}{ CV $(\%)$} \\
\hline & NT & $\mathrm{CC}$ & UR & FOS & $\mathrm{ACL}$ & \\
\hline SR $(\mathrm{kg})$ & 0,272 & 0,251 & 0,247 & 0,263 & 0,247 & 15,70 \\
\hline Glândula mamária $(\mathrm{kg})$ & 0,056 & 0,047 & 0,037 & 0,053 & 0,045 & 43,00 \\
\hline $\mathrm{T}+\mathrm{E}+\mathrm{P}+\mathrm{L}(\mathrm{kg})$ & 0,531 & 0,526 & 0,503 & 0,532 & 0,527 & 8,54 \\
\hline Fígado $(\mathrm{kg})$ & 0,399 & 0,418 & 0,429 & 0,449 & 0,434 & 15,53 \\
\hline Coração (kg) & 0,115 & 0,108 & 0,117 & 0,122 & 0,120 & 12,22 \\
\hline Rins (kg) & 0,068 & 0,071 & 0,061 & 0,076 & 0,067 & 14,20 \\
\hline Baço (kg) & $0,041^{\mathrm{b}}$ & $0,042^{\mathrm{ab}}$ & $0,048^{\mathrm{ab}}$ & $0,052^{\mathrm{a}}$ & $0,047^{\mathrm{ab}}$ & 14,11 \\
\hline Vesícula biliar $(\mathrm{kg})$ & 0,002 & 0,002 & 0,002 & 0,002 & 0,002 & 0 \\
\hline Diafragma (kg) & 0,120 & 0,117 & 0,129 & 0,128 & 0,116 & 15,71 \\
\hline PTO (kg) & 1,55 & 1,54 & 1,54 & 1,62 & 1,56 & 9,38 \\
\hline PTO/PCAJ (\%) & $5,67^{\mathrm{ab}}$ & $5,34^{\mathrm{b}}$ & $5,89^{\mathrm{a}}$ & $5,41^{\mathrm{b}}$ & $5,34^{\mathrm{b}}$ & 4,23 \\
\hline PTO/PCVZ (\%) & $6,76^{\mathrm{a}}$ & $6,35^{\mathrm{b}}$ & $6,94^{\mathrm{a}}$ & $6,43^{\mathrm{b}}$ & $6,43^{b}$ & 4,12 \\
\hline Rumén-retículo $(\mathrm{kg})$ & $0,598^{\mathrm{ab}}$ & $0,607^{\mathrm{ab}}$ & $0,540 \mathrm{~b}$ & $0,659^{a}$ & $0,633^{\mathrm{ab}}$ & 12,95 \\
\hline Omaso (kg) & 0,060 & 0,066 & 0,071 & 0,071 & 0,074 & 11,77 \\
\hline Abomaso (kg) & 0,118 & 0,129 & 0,140 & 0,107 & 0,122 & 18,12 \\
\hline Intestino delgado (kg) & 0,472 & 0,532 & 0,504 & 0,570 & 0,491 & 14,09 \\
\hline Intestino grosso $(\mathrm{kg})$ & 0,298 & 0,298 & 0,305 & 0,331 & 0,314 & 15,76 \\
\hline Total de vísceras (kg) & 1,55 & 1,63 & 1,56 & 1,74 & 1,63 & 11,90 \\
\hline Vísceras/PVAJ (\%) & 5,68 & 5,72 & 6,02 & 5,81 & 5,59 & 4,96 \\
\hline Vísceras:PCVZ (\%) & 6,77 & 6,80 & 7,08 & 6,91 & 6,75 & 5,60 \\
\hline Sangue (kg) & 0,98 & 1,06 & 1,05 & 1,01 & 1,04 & 11,05 \\
\hline Pele (kg) & 2,24 & 2,38 & 2,28 & 2,46 & 2,51 & 8,03 \\
\hline Patas (kg) & 0,510 & 0,523 & 0,524 & 0,552 & 0,527 & 8,25 \\
\hline Cabeça (kg) & 1,18 & 1,19 & 1,12 & 1,17 & 1,16 & 8,16 \\
\hline Bexiga (kg) & $0,009^{\mathrm{b}}$ & $0,011^{b}$ & $0,011^{\mathrm{b}}$ & $0,012^{\mathrm{b}}$ & $0,017^{\mathrm{a}}$ & 24,59 \\
\hline G omental $(\mathrm{kg})$ & $0,608^{\mathrm{b}}$ & $0,815^{\mathrm{ab}}$ & $0,634^{\mathrm{b}}$ & $0,898^{\mathrm{a}}$ & $0,672^{a b}$ & 22,39 \\
\hline G mesentérica $(\mathrm{kg})$ & 0,465 & 0,525 & 0,409 & 0,512 & 0,415 & 25,84 \\
\hline G perirenal (kg) & 0,467 & 0,520 & 0,397 & 0,514 & 0,517 & 41,59 \\
\hline $\mathrm{G}$ coração $(\mathrm{kg})$ & 0,088 & 0,107 & 0,099 & 0,104 & 0,104 & 19,72 \\
\hline Nódulos (kg) & 0,029 & 0,031 & 0,027 & 0,034 & 0,033 & 16,83 \\
\hline $\mathrm{G}$ total $(\mathrm{kg})$ & 1,66 & 2,00 & 1,57 & 2,06 & 1,74 & 25,51 \\
\hline G total/PVAJ (\%) & 6,09 & 7,23 & 6,14 & 7,07 & 5,99 & 9,36 \\
\hline $\mathrm{G}$ total/PCVZ $(\%)$ & 7,24 & 8,55 & 7,21 & 8,41 & 7,24 & 18,27 \\
\hline
\end{tabular}

Médias dos métodos de destoxificação na mesma linha, seguidas de letras minúsculas diferentes, diferem entre si $(\mathrm{P}<0,05)$ pelo teste de Tukey.

${ }^{1} \mathrm{SR}=$ sistema reprodutor; $\mathrm{T}+\mathrm{E}+\mathrm{P}+\mathrm{L}$ : traquéia + esôfago + pulmões + língua; $\mathrm{PTO}=$ peso total de órgãos; PVAJ = peso vivo ao abate; $P C V Z=$ peso de corpo vazio; $\mathrm{G}=$ gordura.

${ }^{2} \mathrm{NT}=$ ração contendo torta de mamona não tratada; $\mathrm{CC}=$ ração contendo torta de mamona tratada com calcário calcítico; UR = ração contendo torta de mamona tratada com uréia; FOS = ração contendo torta de mamona tratada com fosfato monobicálcico; ACL = ração contendo torta de mamona autoclavada. 
Rev. Bras. Saúde Prod. Anim., Salvador, v.13, n.1, p.283-295 jan/mar, 2012 http://www.rbspa.ufba.br ISSN 15199940

Animais do tratamento fosfato monobicálcico apresentaram maior $(\mathrm{P}<0,05)$ peso de rúmen-retículo em relação aos animais do tratamento ureia. O maior rúmen-retículo está em consonância com maior consumo de FDN por animais do tratamento fosfato monobicálcico $\quad(500,7 \mathrm{~g} /$ dia $)$ que propiciou maior desenvolvimento desse compartimento. Medeiros et al. (2008) verificaram que aumento nos níveis de concentrado na ração $(20 ; 40 ; 60$ e $80 \%$ de concentrado) promoveu redução no peso do omaso $(0,089 ; 0,070 ; 0,057 \mathrm{e}$ $0,058 \mathrm{~g}$ ), além de apresentar, redução, em termos absolutos, no rúmen-retículo $(0,717 ; 0,630 ; 0,652$ e $0,665 \mathrm{~g})$, tendo em vista a redução do teor de FDN, com elevação da participação do concentrado na ração.

Os animais do tratamento fosfato monobicálcico mostraram peso de gordura omental superior $(\mathrm{P}<0,05)$ à testemunha, provavelmente devido ao maior PVAJ absoluto daqueles, em virtude do melhor ganho de peso absoluto desse tratamento, com isto, ocorreu acúmulo de gordura mais precocemente. Alves et al. (2003) verificaram aumento na quantidade de gordura interna com elevação dos níveis de energia da ração, o que acarretou maiores exigências de energia para mantença.

A torta de mamona não tratada, em geral, não prejudicou as características de carcaça e seus não componentes, mas os tratamentos com autoclave ou fosfato monobicálcico proporcionaram maior área de olho de lombo.

\section{REFERENCIAS}

ALVES, K.S.; CARVALHO, F.F.R.; FERREIRA, M.A.; VÉRAS, A.S.C.; MEDEIROS, A.N.; NASCIMENTO, J.R.; NASCIMENTO, L.R.S.; ANJOS, A.V.A. Níveis de energia em dietas para ovinos Santa Inês: características de carcaça e constituintes corporais.

Revista Brasileira de Zootecnia, v.32, n.6, p.1927-1936, 2003.

ANANDAN, S.; ANIL, K.G.K.; GHOSH, J.; RAMACHANDRA, K.S. Effect of different physical and chemical treatments on detoxification of ricin in castor cake. Animal Feed Science and Technology, v.120, n.1, p.159-168, 2005.

ASLANI. M.R.; MALEKI, M.; MOHRI, M.; SHARIFI, K.; NAJJARNEZHAD, V.; AFSHARI, E. Castor Bean (Ricinus communis) toxicosis in a sheep flock. Toxicosis, v.49, n.1, p.400406, 2007.

AUDI, J.; BELSON, M.; PATEL, M.; SCHIER, J.; OSTERLOH, J. Ricin Poisoning: a comprehensive review. The Journal of the American Medical Association, v.294, n.18, p.2342-2351, 2005.

BERG, R.T.; BUTTERFIELD, R.M. New concepts of cattle growth.

Sydney: Sydney University Press, 1976. 240p.

BURRIN, D.G.; FERREL, C.L.; BRITTON, R.A.; BAUER, M. Level of nutrition and visceral organ size and metabolic activity in sheep. British Journal of Nutrition, v.64, p.439-448, 1990. 
Rev. Bras. Saúde Prod. Anim., Salvador, v.13, n.1, p.283-295 jan/mar, 2012 http://www.rbspa.ufba.br ISSN 15199940

DINIZ, L.L.; VALADARES FILHO, S.C.; OLIVEIRA, A.S.; PINA, D.S.; SILVA, L.D.; BENEDETI, P.B.; BAIÃO, G.F.; CAMPOS, J.M.S.; VALARES, R.F.D. Castor bean meal for cattle finishing: 1-Nutritional parameters. Livestock Science, v.135, n.2, p.153-167, 2010.

FERREL, C.L.; JENKINS, T.J. Cow type and the nutricinal environment nutritional aspects. Journal of Animal Science, v.61, n.3, p.725-733, 1985.

FRESCURA, R.B.M.; PIRES, C.C.; SILVA, J.H.S.; MÜLLER, L.; CARDOSO A.; KIPPERT, C.J.; PERES NETO, D.; SILVEIRA, C.D. da; ALEBRANTE, L.; THOMAS, L. Avaliação da proporção dos cortes da carcaça, características da carne e avaliação dos componentes do peso vivo de cordeiros. Revista Brasileira de Zootecnia, v.34, n.4, p.167-174, 2005.

FURTADO, R.N. Valor nutricional de rações totais contendo torta de mamona submetida a métodos alternativos de destoxificação para ovinos. 2010. 82p. Dissertação (Mestrado) - Universidade Federal do Ceará, Fortaleza.

GETTY, R. Anatomia dos animais domésticos. Rio de Janeiro: Guanabara Koogan, 1986. 1134p.

GONZAGA NETO, S.; SILVA SOBRINHO, A.G.; ZEOLA, N.M.B.L.; MARQUES, C.A.T.; SILVA, A.M.A.; PEREIRA FILHO, J.M.; FERREIRA, A.C.D. Características quantitativas da carcaça de cordeiros deslanados de Morada Nova em função da relação volumoso:concentrado na dieta. Revista Brasileira de Zootecnia, v.35, n.4, p.1487-1495, 2006.
KABAT, E.A.; HEIDELBERGER, M.; BEZER, A.E. A study of the purification and properties of ricin. Journal of Biological Chemistry, v.168, n.2, p.629-639, 1947.

LEHNINGER, A.L. NELSON, D.L.; COX, M.M. Princípios de

Bioquímica. 2.ed. São Paulo: Sarvier, 1995. 840p.

MACEDO, V.P.; SILVEIRA, A.C.; GARCIA, C.A.; MONTEIRO, A.L.G.; MACEDO, F.A.F.; SPERS, R.C. Desempenho e características de carcaça de cordeiros alimentados em comedouros privativos recebendo rações contendo sementes de girassol.

Revista Brasileira de Zootecnia, v.37, n.11, p.2041-2048, 2008.

MEDEIROS, G.R.; CARVALHO, F.F.R.; FERREIRA, M.A.; ALVES, K.S.; MATTOS, C.W.; SARAIVA, T.A.; NASCIMENTO, J.F. Efeito dos níveis de concentrado sobre sobre os componentes não-carcaça de ovinos Morada Nova em confinamento.

Revista Brasileira de Zootecnia, v.37, n.6, p.1063-1071, 2008.

MEDEIROS, G.R.; CARVALHO, F.F.R.; BATISTA, A.M.V.; DUTRA JÚNIOR, W.M.; SANTOS, G.R.A.; ANDRADE, K.B. Efeito dos níveis de concentrado sobre as características de carcaça de ovinos Morada Nova em confinamento. Revista Brasileira de Zootecnia, v.38, n.4, p.718-727, 2009.

NATIONAL RESEARCH COUNCIL - NRC. Nutrient requeriments of small ruminants. National Academy Press Washington: National Academy Press, 2007. 362p. 
Rev. Bras. Saúde Prod. Anim., Salvador, v.13, n.1, p.283-295 jan/mar, 2012 http://www.rbspa.ufba.br ISSN 15199940

OLIVEIRA, A.S.; CAMPOS, J.M.S.; OLIVEIRA, M.R.C.; BRITO, A.F.; VALADARES FILHO, S.C.; DETMANN, E.; VALADARES, R.F.D.; SOUZA, S.M.; MACHADO, O.L.T. Nutrient digestibility, nitrogen metabolism and hepatic function of sheep fed diets containing solvent or expeller castorseed meal treated with calcium hydroxide. Animal Feed Science and Technology, v.158, p.1528, 2010.

OLIVEIRA, A.S.; OLIVEIRA, M.R.C.; CAMPOS, J.M.S.; LANA, R.P.; MACHADO, O.L.T.; RETAMAL, C.A.; DETMANN, E.; VALADARES FILHO, S.C. In vitro ruminal degradation of ricin and its effect on microbial growth. Animal Feed Science and Technology, v.157, p.41$54,2010$.

OSÓRIO, J.C.S.; OLIVEIRA, N.M.; OSÓRIO, M.T.M.; JARDIM, R.D.; PIMENTEL, M.A. Produção de carne em cordeiros cruza Border Leicester com ovelhas Corriedale e Ideal. Revista Brasileira de Zootecnia, v.31, n.3, p.1469-1480, 2002.

PINHEIRO, R.S.B.; SOBRINHO, A.G.S.; YAMAMOTO, S.M.; BARBOSA, J.C. Composição tecidual dos cortes da carcaça de ovinos jovens e adultos. Pesquisa Agropecuária Brasileira, v.42, n.4, p.565-571, 2007.

REIS, W.; JOBIM, C.C.; MACEDO, F.A.F.; MARTINS, E.N.; CECATO, U. Características da carcaça de cordeiros alimentados com dietas contendo grãos de milho conservados em diferentes formas. Revista Brasileira de Zootecnia, v.30, n.4, p.1308-1315, 2001.

\section{SAS INSTITUTE. SAS system for windows. Version 9.1. Cary, 2003.}

SIQUEIRA, E.R.; SIMÕES, C.D.; FERNANDES, S. Efeito do sexo e do peso ao abate sobre a produção de carne de cordeiro. Morfometria da carcaça, pesos dos cortes, composição tecidual e componentes não constituintes da carcaça. Revista Brasileira de Zootecnia, v.30, n.4, p.1299-1307, 2001.

VIEIRA, M.M.M.; CÂNDIDO, M.J.D.; BOMFIM, M.A.D.; SEVERINO, L.S.; ZAPATA, J.F.F.; BESERRA, L.T.; MENESES, A.J.G.; FERNANDES, J.P.B. Características da carcaça e dos componentes não-carcaça em ovinos alimentados com rações à base de farelo de mamona. Revista Brasileira de Saúde e Produção Animal [Online], v.11, n.1, p.140-149, 2010.

ZUNDT, M.; MACEDO, F.A.F.; MARTINS, E.N.; MEXIA, A.A.; NIETO, L.M.; YAMAMOTO, S.M.; MACEDO, R.M.G. Características de carcaça de cordeiros terminados em confinamento, com dietas contendo diferentes níveis protéicos. Ciência Rural, v.33, n.3, p.565-571, 2003.

Data de recebimento: 05/10/2011

Data de aprovação: 30/01/2012 